\title{
Kesiapan Sumber Daya Manusia Kesehatan dalam Menghadapi Masyarakat Ekonomi Asean (MEA)
}

\author{
Aragar Putri* \\ *Penulis Korespondensi: aragar.putri@gmail.com \\ * Program Studi Kedokteran, Fakultas Kedokteran dan Kesehatan Universitas Muhammadiyah Jakarta

\begin{tabular}{l}
\hline $\boldsymbol{I} \boldsymbol{N D} \boldsymbol{E} \boldsymbol{X I N G}$ \\
\hline Keywords: \\
Asean Economic \\
Community; \\
Human Resources for \\
Health; \\
Globalization
\end{tabular}

\begin{abstract}
A B S TR A C T
Health Human Resources are the backbone of the health care efforts face an increase in the number and proportion of productive age population and the elderly in the future mendatang. Terutama in the face of the Asean Economic Community. Health Human Resources, aims to produce human resources that develop and update health science and technology in the field of health promotion. HRH able to identify and formulate solutions development and management of health human resources through research, develop / improve the performance of professional indicated by the sharpness of the analysis of health problems, formulate and advocate for programs and health policies for the development and management of health human resources.
\end{abstract}

Kata kunci:

Masyarakat Ekonomi Asean; Sumber Daya Manusia Kesehatan; Globalisasi

\begin{abstract}
Sumber Daya Manusia Kesehatan merupakan tulang punggung dalam upaya pelayanan kesehatan menghadapi peningkatan jumlah dan proporsi penduduk usia produktif dan lanjut usia di masa mendatang.Terutama dalam menghadapi Masyarakat Ekonomi Asean. Sumber Daya Manusia Kesehatan, bertujuan untuk menghasilkan sumber daya manusia kesehatan yang mengembangkan dan memutakhirkan ilmu pengetahuan dan teknologi di bidang promosi kesehatan. SDM Kesehatan mampu mengidentifikasi dan merumuskan pemecahan masalah pengembangan dan pengelolaan sumber daya manusia kesehatan melalui kegiatan penelitian, mengembangkan/meningkatkan kinerja profesionalnya yang ditunjukkan dengan ketajaman analisis permasalahan kesehatan, merumuskan dan melakukan advokasi program dan kebijakan kesehatan dalam rangka pengembangan dan pengelolaan sumber daya manusia kesehatan.
\end{abstract}

(C) 2017 JMMR. All rights reserved

\section{PENDAHULUAN}

Sehat merupakan kondisi optimal fisik, mental dan sosial seseorang sehingga dapat memiliki produktivitas, bukan hanya terbebas dari bibit penyakit. Kondisi sehat dapat dilihat dari dimensi produksi dan dimensi konsumsi. Dimensi produksi memandang keadaan sehat sebagai salah satu modal produksi atau prakondisi yang dibutuhkan seseorang sehingga dapat beraktivitas yang produktif.

Undang Undang Republik Indonesia No 36 tahun 2009 tentang kesehatan, yang dimaksud dengan tenaga kesehatan adalah setiap orang yang mengabdikan diri dalam bidang kesehatan serta memiliki pengetahuan dan/atau keterampilan melalui pendidikan di bidang kesehatan yang untuk jenis tertentu memerlukan kewenangan untuk melakukan upaya kesehatan. ${ }^{1}$
Upaya kesehatan adalah setiap kegiatan dan/atau serangkaian kegiatan yang dilakukan secara terpadu, terintegrasi dan berkesinambungan untuk memelihara dan meningkatkan derajat kesehatan masyarakat dalam bentuk pencegahan penyakit, peningkatan kesehatan, pengobatan penyakit, dan pemulihan kesehatan oleh pemerintah dan/atau masyarakat.

Kesehatan masyarakat adalah ilmu dan seni untuk mencegah penyakit, memperpanjang hidup, mempromosikan kesehatan dan efisiensi dengan menggerakkan potensi seluruh masyarakat. Konsep kesehatan masyarakat berkaitan dengan perubahan perilaku sehat akan lebih terbentuk dan bertahan lama bila dilandasi kesadaran sendiri (internalisasi) sehingga konsep upaya sehat dari, oleh dan untuk masyarakat sangat tepat diterapkan.

Saat ini pemerintah Indonesia yang tergabung dalam Masyarakat Ekonomi Asean (MEA) bersiap diri 
meningkatan Sumber Daya Manusia Kesehatan (SDMK) sebagai modal agar bisa bersaing dalam perdagangan global. Sumber Daya Manusia Kesehatan merupakan ujung tombak pelayanan kesehatan di lapangan, baik preventif, promotif, kuratif, dan rehabilitatif. Sumber Daya Manusia Kesehatan juga merupakan unsur utama peningkatan daya saing pelayanan kesehatan. Sumber Daya Manusia Kesehatan merupakan tulang punggung upaya pelayanan kesehatan menghadapi peningkatan jumlah dan proporsi penduduk usia produktif dan lanjut usia di masa mendatang.

Sumber Daya Manusia Kesehatan, bertujuan untuk menghasilkan sumber daya manusia kesehatan yang memiliki kompetensi sebagai berikut :

1) Mampu mengembangkan dan memutakhirkan ilmu pengetahuan dan teknologi di bidang promosi kesehatan dengan cara menguasai dan memahami pendekatan, metode dan kaidah ilmiahnya disertai dengan ketrampilan penerapannya didalam pengembangan dan pengelolaan sumber daya manusia kesehatan.

2) Mampu mengidentifikasi dan merumuskan pemecahan masalah pengembangan dan pengelolaan sumber daya manusia kesehatan melalui kegiatan penelitian.

3) Mengembangkan/meningkatkan kinerja profesionalnya yang ditunjukkan dengan ketajaman analisis permasalahan kesehatan, merumuskan dan melakukan advokasi program dan kebijakan kesehatan dalam rangka pengembangan dan pengelolaan sumber daya manusia kesehatan.

Subsistem SDM Kesehatan bertujuan tersedianya kesehatan yang kompeten sesuai kebutuhan yang terdistribusi secara adil dan merata serta didayagunakan secara optimal dalam mendukung penyelenggarakan pembangunan kesehatan guna mewujudkan derajat kesehatan yang setinggi tingginya. Unsur yang terlibat diantaranya Sumber Daya Manusia Kesehatan, Sumber Daya pengembangan dan pemberdayaan SDM Kesehatan ditambah unsur penyelenggaraan pengembangan dan pemberdayaan SDM Kesehatan. Penyelengaraan keseluruhan dari rencana subsistem tersebut dengan adanya perencanaan SDM Kesehatan, Pengadaan SDM Kesehatan, Pendayagunaan SDM
Kesehatan dan sekaligus Pembinaan dan Pengawasan SDM Kesehatan.

Pada Konferensi Tingkat Tinggi (KTT) ASEAN yang ke-12 di bulan Januari 2007, para pemimpin mulai menegaskan komitmen mereka tentang mela-kukan percepatan pembentukan komunitas ASEAN di tahun 2015 yang telah diusulkan oleh ASEAN Vision 2020 dan ASEAN Concord II, dan adanya penandatanganan deklarasi CEBU di Filipina menge-nai percepatan pembentukan komunitas ekonomi ASEAN di tahun 2015 untuk melakukan pengubahan ASEAN menjadi suatu daerah perdagangan yang bebas barang, investasi, tenaga kerja terampil, jasa dan aliran modal yang lebih bebas lagi. ${ }^{2}$

Masyarakat Ekonomi ASEAN ialah suatu realisasi dari tujuan akhir (MEA) terhadap integrasi ekonomi yang telah dianut didalam ASEAN Visi 2020 yang berdasarkan atas konvergensi kepentingan para negaranegara anggota ASEAN untuk dapat memperluas dan memperdalam integrasi ekonomi lewat inisiatif yang ada dan baru dengan memiliki batas waktu yang jelas. Didalammendirikan masyarakat ekonomi ASEAN atau MEA, ASEAN mesti melakukan indakan sesuai dengan pada prinsip-prinsip terbuka, berorientasi untuk mengarah ke luar, terbuka, dan mengarah pada pasar ekonomi yang teguh pendirian dengan peraturan multilateral serta patuh terhadap sistem untuk pelaksanaan dan kepatuhan komitmen ekonomi yang efektif berdasarkan aturan.

\section{Permasalahan}

Berdasarkan paparan di atas, maka rumusan masalah yang akan dijaki pada paper ini adalah sebagai berikut:

1. Bagaimana Kesiapan Sumber Daya Manusia Kesehatan Dalam menghadapi Masyarakat Ekonomi Asean berdasarkan Kebijakan Pembangunan Sumber Daya Manusia Kesehatan?

2. Di saat masih banyaknya masalah bangsa, bangsa kita akan menghadapi masyarakat ekonomi Asean (MEA) 2015.

3. Bagaimanakah peran SDM Kesehatan dalam menghadapi Masyarakat Ekonomi Asean (MEA)? 
Indeks Pembangunan Manusia Indonesia dari tahun ke tahun meningkat, walaupun saat ini Indonesia masih berada pada ranking 108 dari 187 negara di dunia. Pembangunan manusia pada dasarnya adalah upaya untuk memanusiakan manusia kembali. Adapun upaya yang dapat ditempuh harus dipusatkan pada seluruh proses kehidupan manusia itu sendiri, mulai dari bayi dengan pemberian ASI dan imunisasi hingga lanjut usia, dengan memberikan jaminan sosial. Kebutuhankebutuhan pada setiap tahap kehidupan harus terpenuhi agar dapat mencapai kehidupan yang lebih bermartabat.

Dalam rangka mendorong pembangunan manusia secara menyeluruh, perlu perhatian pada kesehatan sejak dini atau sejak Balita. Kita lihat bahwa sangat penting untuk melakukan investasi yang tepat waktu agar pertumbuhan otak anak sampai usia 5 tahun dapat berjalan dengan baik, untuk menghindari loss generation. Salah satu ancaman serius terhadap pembangunan kesehatan, khususnya pada kualitas generasi mendatang, adalah stunting. Dimana rata-rata angka stunting di Indonesia sebesar 37.2\%. Menurut standar WHO, persentase ini termasuk kategori berat. ${ }^{3}$

Visi dari pembangunan kesehatan adalah menciptakan masyarakat sehat yang mandiri dan berkeadilan. Sedangkan Misinya adalah Indonesia yang berdaulat, mandiri, dan berkepribadian berdasarkan gotong royong, mewujudkan masyarakat maju yang berkesinambung dan demokratis.

\section{Kebijakan Pembangunan Sumber Daya Manusia Kesehatan}

Setiap upaya pembangunan harus dilandasi dengan wawasan kesehatan dalam arti pembangunan nasional harus memperhatikan kesehatan masyarakat dan merupakan tanggungjawab semua pihak baik pemerintah maupun masyarakat. Untuk mewujudkan maka dibuat Rancangan Pembangunan Jangka Menengah Nasional (RPJMN) 1-4. Arah pembangunan kesehatan yang terdapat dalam RPJMN 1 2005-2009 mengacu pada pembangunan kesehatan yang terfokus pada peningkatan akses dan mutu pelayanan kesehatan. Sedangkan arah pembangunan kesehatan dalam RPJMN ke 2 tahun 2010-2014, akses masyarakat terhadap pelayanan kesehatan yang berkualitas telah lebih berkembang dan meningkat. Dalam RPJMN ke 3 tahun 2015-2019 akses masyarakat terhadap pelayanan yang berkualitas telah mulai mantap. Dan pada RPJMN 4 tahun 2020-2025 kesehatan masyarakat terhadap pelayanan kesehatan yang berkualitas telah menjangkau dan merata di seluruh wilayah Indonesia.Upaya pengembangan kesehatan dari kuratif bergerak kearah promotif dan preventif sesuai kondisi dan kebutuhan. ${ }^{4}$

Di era masyarakat ekonomi ASEAN, persaingan perdagangan dan jasa termasuk disektor kesehatan akan semakin kompetitif dan hanya negara dengan pemerintah daerahnya yang siap saja yang akan mampu berkompetisi dan meraup keuntu-ngannya. Potensi keuntungan dapat berupa terciptanya lapangan kerja yang luas pada sarana-sarana pelayanan kesehatan, meningkatnya kualitas pelayanan kesehatan dan derajat kesehatan masyarakat dan mengurangi kemiskinan serta kesenjangan sosial ekonomi, Secara makro, imbas positifnya juga pada peningkatan pendapatan ekonomi rakyat dan pertumbuhan ekonomi yang tinggi karena mendatangkan devisa yang besar bagi negara atau PAD bagi daerah, perluasan cakupan skala ekonomi, meningkatkan daya tarik sebagai tujuan bagi investor dan wisatawan, mengurangi biaya transaksi perdagangan, serta dapt juga digunakan untuk memperbaiki fasilitas perdagangan dan bisnis. Di samping itu, juga akan memberikan kemudahan dan peningkatan akses pasar termasuk pasar jasa kesehatan.

\section{Persiapan Indonesia di bidang Kesehatan menghadapi MEA}

Jauh sebelum adanya kesepakatan masuknya Indonesia dalam Masyarakat Ekonomi Asean, dari Kementerian Kesehatan telah membuat Rancangan sistem kesehatan nasional yang dimulai dari tahun 2005-2025. Sistem Kesehatan Nasional sebagai landasan pikir RPJMN tahap ke 3 (2015-2019) dimana untuk mencapai upaya kesehatan yang maksimal dibutuhkan manajemen kesehatan yang terdiri dari SDM kesehatan, farmasi dan askes serta makanan, penelitian dan pengembangan serta pemberdayaan masyarakat, juga diperlukan pembiayaan kesehatan termasuk jaminan kesehatan nasional. - Dengan terpenuhinya kebutuhan manajemen dan pembiayaan kesehatan maka akan tercapai derajat kesehatan masyarakat, perlindungan finansial dan responsiveness pelayanan kesehatan sesuai yang terdapat di dalam peraturan presiden No 72 tahun 2012 . 
Seperti diketahui bahwa beberapa negara sudah mengembangkan paket wisata medis (Medical Tourism) seperti tootache tourism, pregnancy tourism, plastic surgery tourism dan lainnya dalam menghadapi Masyarakat Ekonomi Asean. Indonesia juga perlu mengembangkan skema medical tourism yang terintegrasi dan terkelola baik. Singapura, Malaysia dan Thailand sudah lebih dulu mengembangkan medical tourism nya dengan rumah sakit bertaraf internasional yang banyak didatangi pasien luar negeri. Indonesia harus bisa mengimbangi dan menyiapkan diri agar bisa memberikan jaminan kualitas pelayanan, fasilitas yang mendukung, penjaminan mutu, dan penawaran program khusus dapat menarik wisata medis dari berbagai negara ASEAN untuk berkunjung ke Indonesia.

Upaya mengantisipasi keberadaan MEA terhadap kesiapan SDM Kesehatan ada beberapa tantangan yang dihadapi dengan cara mengupayakan Sistem Layanan Kesehatan secara maksimal. Langkah yang bisa dijalankan dengan cara menyiapkan infrastruktur, disparitas antar wilayah, regulasi, sistem koordinasi dan sistem monitoring evaluasi. Sumber Daya Manusia (SDM) kesehatan dalam tahapan RPJPK tahun 20102014 telah melaksanakan tenaga kesehatan pada sebagian besar daerah tertinggal, perbatasan dan kepulauan (DTPK), selain itu di pusat dan provinsi mempunyai perencanaan SDM dan Sistem Informasi SDM Kesehatan. Pada tahapan ini juga dilengkapi dengan pendidikan dan latihan sesuai dengan kebutuhan dan system pendidikan nasional, juga adanya pembinaan dan pengawasan. $-\underline{6}$

Tahapan RPJMN tahun 2015-2019 pemenuhan tenaga kesehatan untuk seluruh daerah tertinggal perbatasan dan kepulauan (DTPK), perencanaan SDM Kesehatan dan sistem Informasi sudah mencakup seluruh kabupaten dan kota. Adanya pelaksanaan distribusi serta manajemen karir juga adanya sinergi pengadaan SDM Kesehatan dan adanya pembinaan serta pengawasan. Pada tahapan RPJMN tahun 20202025 diharapkan kebutuhan seluruh SDM kesehatan dapat terpenuhi dan terintegrasi secara nasional, pengadaan SDM Kesehatan sesuai dengan kebutuhan, pemantapan distribusi dan manajemen karir juga tetap adanya pembinaan dan pengawasan. ${ }^{?}$

Saat ini pendayagunaan SDM Kesehatan mempunyai prinsip; 1). Merata, serasi, seimbang (pemerintah, swasta, masyarakat) lokal maupun pusat. 2). Pemeratan: keseimbangan hak dan kewajiban. 3)
Pendelegasian wewenang yang proporsional. Sedangkan secara terperinci dapat digambarkan perkembangan dan hambatan situasi sumber daya kesehatan sebagai berikut: 1) Tenaga kesehatan merupakan bagian terpenting didalam peningkatan pelayanan kesehatan di Kabupaten Tangerang, peningkatan kualitas harus menjadi prioritas utama mengingat tenaga kesehatan saat ini belum sepenuhnya berpendidikan D-III serta S1 sedangkan yang berpendidikan SPK serta sederajat minim terhadap pelatihan tehnis, hal ini juga berkaitan dengan globalisasi dunia dan persaingan terhadap kualitas ketenagaan harus menjadi pemicu. 2). Pembiayaan kesehatan terhadap pelayanan kesehatan menjadi salah satu faktor utama didalam peningkatan pelayanan kesehatan, baik untuk belanja modal maupun belanja barang. Didalam upaya peningkatan pembiayaan terhadap sektor kesehatan dianggarkan melalui dana APBN, APBD Provinsi dan Kabupaten, serta sumber lainnya. 3) Komponen laindidalam sumber daya kesehatan yang paling penting adalah ketersedian sarana kesehatan yang cukup secara jumlah/kuantitas dan kualitas bangunan yang menggambarkan unit sarana pelayanan kesehatan yang bermutu baik bangunan utama, pendukung dan sanitasi kesehatan lingkungan. Pembangunan sarana kesehatan harus dilengkapi dengan peralatan medis, peralatan nonmedis, peralatan laboratorium beserta reagensia, alat pengolah data kesehatan, peralatan komunikasi, kendaraan roda empat dan kendaraan roda dua.

\section{Peran SDM Kesehatan Menghadapi MEA}

Peran SDM Kesehatan menghadapi MEA diantaranya mengadvokasi pemerintah bahwa program Indonesia sehat yang dicita citakan Kementrian Kesehatan adalah sejalan dengan cita-cita MEA yang menekankan pada upaya promosi untuk hidup sehat. SDM Kesehatan berperan juga mengurus dan mengupayakan promotif preventif kesehatan masyarakat. Tercantum dalam Asean strategic Framework on Health Development (2010-2015). ${ }^{-}$ Area kerjasama Asean bidang kesehatan termasuk akses pelayanan kesehatan dan promosi prilaku sehat serta peningkatan kemampuan pengendalian penyakit menular.

Peran selanjutnya adalah mendorong pergeseran anggaran dari upaya kuratif dan rehabilitatif ke arah promotif dan preventif. Saat ini Kementrian Kesehatan 
telah menganut paradigm sehat tetapi anggaran untuk promotif dan preventif masih belum mmencukupi. Dalam era MEA upaya kuratif lebih diprioritaskankarena terkait dengan "bisnis" alat dan fasilitas kesehatan. Tenaga kesehatan masyarakat mempertahankan anggaran untuk promotif dan preventif agar ditingkatkan untuk usaha kecil dan menengah (UKM).

SDM Kesehatan masyarakat juga berperan dalam standarisasi mutu menuju daya saing global. Oleh sebab itu tenaga kesehatan masyarakat harus memenuhi antara lainstandarisasi dan sertifikasi agar siap uji kompetensi dan memiliki Surat Tanda Regristasi (STR) dan Institusi Pendidikan Kesehatan harus terakreditasi perguruan tinggi. Tidak kalah penting SDM Kesehatan masyarakat merupakan konsultan kesehatan dalam menata program-program pembangunan kesehatan dari mulai perencanaan hingga evaluasi sektor kesehatan. Saat ini Kementerian Kesehatan melalui program MTAF sedang mendata konsultan kesehatan masyarakat dan ahlinya.

SDM Kesehatan memiliki peran sebagai penata system informasi dan mengumpulkan data kesehatan.Kementrian Kesehatan mulai merancang untuk ke depannya di era Informasi Teknologi semua data kesehatan dengan mengembangkan website dan sosial media sebagai wadah untuk penguatan promosi kesehatan. Data tenaga kesehatan akan lebih dinamis karena pesatnya arus keluar masuk tenaga kesehatan. Pada akhirnya SDM Kesehatan dapat berperan untuk memastikan pelayanan kesehatan yang diberikan adalah biaya yang efektif dan efisien serta berkesinambungan.

\section{SIMPULAN}

Berdasarkan paparan di atas dapat disimpulkan bahwa pemerintah Indonesia dari Kementrian Kesehatan melalui SDM Kesehatan telah menyiapkan kebijakan kesehatan dalam rangka menghadapi masyarakat ekonomi Asean. Adapun langkah yang sudah diambil berupa Rancangan Pembangunan Jangka Menengah Nasional (RPJMN) 1-4, mengacu pada pembanguan kesehatan yang terfokus pada peningkatan akses dan mutu pelayanan kesehatan, akses masyarakat terhadap pelayanan kesehatan yang berkualitas telah lebih berkembang dan meningkat, akses masyarakat terhadap pelayanan yang berkualitas telah mulai mantap, dan diharapkan kesehatan masyarakat terhadap pelayanan kesehatan yang berkualitas telah menjangkau dan merata di seluruh wilayah Indonesia. Upaya pengembangan kesehatan dari kuratif bergerak kearah promotif dan preventif sesuai kondisi dan kebutuhan.

Peran SDM Kesehatan menghadapi MEA diantaranya mengadvokasi pemerintah bahwa program Indonesia sehat yang dicita citakan Kementerian Kesehatan adalah sejalan dengan cita-cita MEA yang menekankan pada upaya promosi untuk hidup sehat dan juga berperan dalam standarisasi mutu menuju daya saing global. Upaya intensif dan masif perlu dilakukan Pemerintah dengan melakukan sosialisasi tentang MEA, pengalokasian anggaran kesehatan yang memadai untuk meningkatkan soft skill, hard skill dan kesejahteraan tenaga medis, koordinasi yang baik antara pemerintah pusat dan daerah, serta melakukan transformasi cetak biru MEA ke dalam hukum nasional, semuanya harus terakselerasi secara dinamis dan harmonis karena bernilai strategis terhadap daya saing Indonesia disektor kesehatan dalam ajang kompetisi masyarakat ekonomi ASEAN.

\section{DAFTAR PUSTAKA}

1. Undang Undang Republik Indonesia No 36 tahun 2009 Tentang Kesehatan

2. Arah Kebijakan dan Strategi Program Pengembangan dan Pemberdayaan SDM Kesehatan tahun 2015-2019, Oleh Kepala Badan PPSDM Kesehatan, Jakarta, 22 April 2015.

3. Astiena, dr. Adila Kasni, MARS. 2009. Materi Kuliah Sumber Daya Manusia Kesehatan. Program Studi Ilmu Kesehatan Masyarakat Universitas Andalas

4. https://catatankuliahnya.wordpress.com/2010/01/ 06/sumber-daya-manusia-kesehatan/

5. http://www.observatorisdmkindonesia.org/wpcontent/uploads/2014/08/KebijakanImplementasi-Pengembangan-SDMK.pdf

6. Kebijakan Pembangunan SDM Kesehatan Dalam Draf Rancangan RPJMN 2010-2014 dan Pendekatan Kewilayahan.

7. Kebijakan dan Implementasi Pengembangan SDM Kesehatan, Lokakarya Nasional Pengembangan dan Pemberdayaan SDM Kesehatan, Jakarta 27 Agustus 2014. 
8. "Manajemen Sumber Daya Manusia Kesehatan

Masyarakat" dikutip dari

http://www.toodoc.com/ 5 Agustus 2016. 19:06

$W I B$

9. "Pemanfaatan dan Pemberdayaan Sumber Daya Kesehatan" dikutip dari http://www.perpustakaan-depkes.5 Agustus 2016. 14;20 WIB

10. Rencana Aksi Kegiatan 2015-2019, Pusat Pembiayaan dan Jaminan Kesehatan Oleh dr Donald Pardede MPPM.

11. Rencana Strategis Kementrian Kesehatan Tahun 2015-2019 , Keputusan Menteri Kesehatan Indonesia No HK.02-02/52/2015.

12. "Sumber Daya Manusia dalam Pengembangan Sistem Informasi Kesehatan Daerah” dikutip dari http://simkesugm06.wordpress.com 5 Agustus 2016. 15:14 WIB. 